\title{
Role of Intact Cardiac Nerves and Reflex Mechanisms in Desensitization to Catecholamines in Conscious Dogs
}

Jun Nejima, Nobuhisa Uemura, Dorothy E. Vatner, Charles J. Homcy, Thomas H. Hintze, and Stephen F. Vatner Departments of Medicine, Harvard Medical School, Brigham \& Women's Hospital, Boston, Massachusetts 02115; and the New England Regional Primate Research Center, Southborough, Massachusetts 01772

\section{Abstract}

To study chronic catecholamine desensitization, mini-osmotic pumps were implanted subcutaneously to deliver $\mathrm{NE},(0.5$ $\mu \mathrm{g} / \mathrm{kg} / \mathrm{min}$ ) or saline over 3-4 wk in dogs instrumented with left ventricular (LV) pressure gauges and arterial and left atrial pressure catheters. An acute challenge to $\mathrm{NE}(0.4 \mu \mathrm{g} / \mathrm{kg} / \mathrm{min})$ in intact, conscious dogs increased $\mathrm{LV} \mathrm{dP} / \mathrm{dt}$ by $1,531 \pm 208$ $\mathrm{mmHg} / \mathrm{s}$ before $\mathrm{NE}$ pumps, and by a similar amount, $1,340 \pm 166 \mathrm{mmHg} / \mathrm{s}, 3-4$ wk after $\mathrm{NE}$ pumps. In contrast, an acute challenge to isoproterenol (ISO, $0.4 \mu \mathrm{g} / \mathrm{kg} / \mathrm{min}$ ) increased $\mathrm{LV} \mathrm{dP} / \mathrm{dt}$ by $5,344 \pm 532 \mathrm{mmHg} / \mathrm{s}$ before $\mathrm{NE}$ pumps, and significantly less $(P<0.05 ; 2,425 \pm 175 \mathrm{mmHg} / \mathrm{s})$ after $\mathrm{NE}$ pumps. In the presence of ganglionic and $\alpha_{1}$-adrenergic blockades, NE (0.4 $\mathrm{\mu g} / \mathrm{kg} / \mathrm{min})$ increased $\mathrm{LV} \mathrm{dP} / \mathrm{dt}$ by $3,656 \pm 468 \mathrm{mmHg} / \mathrm{s}$ before $\mathrm{NE}$ pumps and significantly less $(P<0.01 ; 1,459 \pm 200 \mathrm{mmHg} / \mathrm{s})$ after $\mathrm{NE}$ pumps. Confirming this, an acute challenge to $\mathrm{NE}(0.4 \mu \mathrm{g} / \mathrm{kg} / \mathrm{min})$ in dogs with arterial baroreceptor denervation increased $\mathrm{LV} \mathrm{dP} / \mathrm{dt}$ by $3,732 \pm 896 \mathrm{mmHg} / \mathrm{s}$ before $\mathrm{NE}$ pumps, and significantly less $(P<0.05,1,725 \pm 408 \mathrm{mmHg} / \mathrm{s})$ after $\mathrm{NE}$ pumps. In addition, in cardiac denervated dogs, $\mathrm{NE}(0.4 \mu \mathrm{g} / \mathrm{kg} / \mathrm{min})$ increased $\mathrm{LV}$ $\mathrm{dP} / \mathrm{dt}$ by $9,901 \pm 1,404 \mathrm{mmHg} / \mathrm{s}$ before $\mathrm{NE}$ pumps and signifcantly less $(P<0.01,2,690 \pm 306 \mathrm{mmHg} / \mathrm{s})$ after $\mathrm{NE}$ pumps. Desensitization of heart rate responses to $\mathrm{NE}$ challenge was also more apparent in the absence of reflex mechanisms. Thus, neural reflex mechanisms play a major role in physiological expression of cardiac desensitization to catecholamines in conscious dogs. (J. Clin. Invest. 1990. 86:2046-2053.) Key words: norepinephrine $\bullet$ left ventricular function $\bullet \beta$-adrenergic receptors $\bullet$ arterial baroreceptor denervation $\bullet$ cardiac denervation

\section{Introduction}

Significantly elevated plasma levels of NE have been observed in various clinical settings, e.g., pheochromocytoma and

Address reprint requests to Dr. Stephen F. Vatner, New England Regional Primate Research Center, One Pine Hill Drive, Southborough, MA 01772.

Dr. Dorothy Vatner is in the Department of Pediatrics, Harvard Medical School and Massachusetts General Hospital, Boston, MA 02114.

Dr. Charles Homcy is in the Department of Medicine, Harvard Medical School and Massachusetts General Hospital, Boston, MA 02114.

Dr. Thomas Hintze is in the Department of Physiology, New York Medical College, Valhalla, NY. 1990.

Received for publication 24 July 1989 and in revised form 26 July

J. Clin. Invest.

(c) The American Society for Clinical Investigation, Inc.

0021-9738/90/12/2046/08 \$2.00

Volume 86, December 1990, 2046-2053 chronic heart failure, which are often accompanied by blunted responses to exogenous catecholamines (1-10). This phenomenon may be a manifestation of catecholamine desensitization, which has been recognized for some time (11-13). Most prior studies examining mechanisms of desensitization were conducted in vitro, or in anesthetized animals (14-23), and have relied primarily on the synthetic $\beta$-adrenergic agonist isoproterenol (ISO), ${ }^{1}$ rather than on the physiological neurotransmitter, NE. The underlying hypothesis of the current investigation was that the mechanism of desensitization to chronic NE would depend upon reflex buffering as well as biochemical mechanisms involving $\beta$-adrenergic receptor pathways in the intact conscious animal, since NE increases arterial pressure and induces baroreflex buffering, resulting in diminished sympathetic neural tone and enhanced parasympathetic restraint. Furthermore, NE is taken up by cardiac nerves, which could affect concentrations of the $\beta$-adrenergic agonist at the postjunctional receptor site. Thus, autonomic reflex mechanisms may be important in understanding mechanisms of catecholamine desensitization in the intact, conscious animal.

Accordingly, the primary goal of the present investigation was to determine whether chronically elevated levels of plasma $\mathrm{NE}$ induced by implantation of mini-osmotic pumps elicit desensitization to inotropic and chronotropic stimulation by catecholamines in intact conscious animals, and second, to determine whether neural mechanisms modify the expression of cardiac desensitization in the conscious animal. A third goal was to determine if neural reflex mechanisms were responsible for the normalization of arterial pressure under conditions of chronic, catecholamine exposure. To achieve these goals, the experiments were conducted in intact dogs, in the presence and absence of ganglionic blockade, and also in dogs with chronic arterial baroreceptor denervation and animals with chronic cardiac denervation. The effects of the mixed $\alpha$ - and $\beta$-adrenergic receptor agonist $\mathrm{NE}$, and the mixed $\beta_{1}$ - and $\beta_{2}$ adrenergic agonist ISO, were examined before and 3-4 wk after implantation of either NE or saline pumps.

\section{Methods}

Preparation of the model. 41 mongrel dogs of either sex (20 intact, 16 cardiac denervated, 5 arterial baroreceptor denervated) were anesthetized with sodium pentobarbital $(30 \mathrm{mg} / \mathrm{kg})$ and ventilated with a respirator. The pericardium, exposed via a left thoracotomy through the fifth intercostal space, was opened. A miniature solid-state pressure gauge (P22; Konigsberg Instruments, Inc., Pasadena, CA) was implanted in the left ventricle (LV) via an apical stab wound. Tygon catheters were implanted in the descending thoracic aorta and left atrium. The second group of 16 dogs (cardiac denervated group) underwent surgical cardiac denervation procedure according to the

1. Abbreviations used in this paper: ISO, isoproterenol; LV, left ventricle. 
method of Randall et al. (24), which has been used previously in our laboratory (25). The intrapericardial denervation technique consisted of $(a)$ section of the ventrolateral cardiac nerve, $(b)$ adventitial stripping of the left superior pulmonary vein and of the right and common pulmonary artery, and $(c)$ section of pericardial reflections in the transverse sinus and around the superior vena cava, as well as ligation and division of the azygos vein. In addition, the ansae were divided bilaterally. One dog with a saline pump in this group died prematurely and could not be included in the pathology data and LV tissue NE content data. A third group of five dogs (arterial baroreceptor denervated group) underwent arterial baroreceptor denervation, which consisted of surgical denervation of the aortic arch and carotid sinuses produced by extensive removal of the adventitia followed by painting of these areas with $2 \%$ phenol to destroy any residual neural tissue (26). The incision was closed in layers, the pneumothorax was reduced, and animals were allowed to recover for $2-4$ wk before experiments. The completeness of cardiac denervation was confirmed by three separate procedures, first at operation, then 2-4 weeks later in the conscious state, and finally, after dogs were killed. First, at operation, after the cardiac denervation procedure, stimulation of the ansa subclaviae and the vagi failed to alter heart rate or $\mathrm{LV} \mathrm{dP/dt}$. Second, in intact conscious dogs, phenylephrine $(5 \mu \mathrm{g} / \mathrm{kg})$ increased mean arterial pressure by $32 \pm 3 \mathrm{mmHg}$ and reduced heart rate by $42 \pm 4$ beats/min, whereas nitroglycerin reduced mean arterial pressure by $32 \pm 2 \mathrm{mmHg}$ and increased heart rate by $81 \pm 6$ beats/min. In dogs with cardiac denervation, phenylephrine increased mean arterial pressure by $49 \pm 5 \mathrm{mmHg}$ and did not decrease heart rate, whereas nitroglycerin reduced mean arterial pressure by $46 \pm 4 \mathrm{mmHg}$ and did not increase heart rate. In dogs with arterial baroreceptor denervation, phenylephrine increased mean arterial pressure by $52 \pm 11 \mathrm{mmHg}$ and did not decrease heart rate, whereas nitroglycerin reduced mean arterial pressure by $50 \pm 4$ $\mathrm{mmHg}$ and did not increase heart rate. Finally, after the animals were killed, $\mathrm{LV}$ tissue $\mathrm{NE}$ levels were $448 \pm 42 \mathrm{pg} / \mathrm{mg}$ wet weight in the intact group, as compared with $6 \pm 2 \mathrm{pg} / \mathrm{mg}$ wet weight in the cardiac denervated group, indicating the completeness of denervation. Animals used in this study were maintained in accordance with the guidelines of the Committee on Animals of the Harvard Medical School and those prepared by the Committee on Care and Use of Laboratory Animals of the Institute of Laboratory Animal Resources, National Research Council, National Institutes of Health (Bethesda, MD).

Measurements. Arterial and left atrial pressures were measured by means of the implanted catheters and Statham P23ID strain gauge manometers (Statham Instruments, Oxnard, CA). LV pressure was measured with the solid-state miniature pressure gauge, which was calibrated in vitro against a mercury manometer as well as in vivo against the arterial and left atrial pressure measurements. The first derivative of $L V$ pressure, $L V \mathrm{dP} / \mathrm{dt}$, was obtained with an operational amplifier connected as a differentiator, which has a frequency response of $700 \mathrm{~Hz}$. A triangular wave signal was substituted for the pressure signal to calibrate the differentiator directly. The data were recorded on a multichannel tape recorder (Honeywell Inc., Denver, $\mathrm{CO}$ ) and played back on a direct-writing oscillograph (Gould-Brush, Cleveland, $\mathrm{OH})$.

Protocol. All dogs were studied before implantation of the pumps in the conscious state 2-4 wk after recovery from operation, and then again 3-4 wk after implantation of the Alzet osmotic infusion pump (Alza, Palo Alto, CA). On the day of the experiment, a control plasma catecholamine sample was taken for later assay of NE levels by the radioenzymatic method of DaPrada and Zurcher (27). Separate infusions of $\mathrm{NE}(0.1,0.2,0.4,0.8 \mu \mathrm{g} / \mathrm{kg} / \mathrm{min})$ were administered for $5 \mathrm{~min}$ while measurements of $L V$ pressure, $L V \mathrm{dP} / \mathrm{dt}$, phasic and mean arterial pressure, left atrial pressure, and heart rate were recorded continuously. Subsequent infusions were not begun until hemodynamics returned to baseline after the preceding drug infusion. ISO $(0.1,0.2,0.4$ $\mu \mathrm{g} / \mathrm{kg} / \mathrm{min}$ ) was administered in the same manner as NE infusions. Since ISO reduces arterial pressure through its $\beta_{2}$-adrenergic vasodilator effects and could affect the utility of $\mathrm{LV} \mathrm{dP/dt}$ as an index of the inotropic state, phenylephrine, an $\alpha_{1}$-adrenergic agonist, was infused simultaneously to maintain arterial pressure at baseline values in all except the first three dogs studied. On a separate day the 5-min infusions of NE and ISO were repeated after ganglionic blockade with hexamethonium bromide $(30 \mathrm{mg} / \mathrm{kg})$ and atropine $(0.1 \mathrm{mg} / \mathrm{kg})$ in five dogs with saline pumps and seven intact dogs with NE pumps. NE infusions were examined in the presence of ganglionic blockade plus $\alpha_{1}$-adrenergic receptor blockade with prazosin $(1.0 \mathrm{mg} / \mathrm{kg})$. Absence of reflex heart rate change in response to changes in arterial pressure induced by phenylephrine and nitroglycerin confirmed the adequacy of the ganglionic blockade. Supplemental doses of hexamethonium were required since these experiments required several hours to complete. In three of the intact dogs, NE infusions were also examined with heart rate held constant by ventricular pacing and also after atropine $(0.1 \mathrm{mg} / \mathrm{kg})$ in the absence of ganglionic blockade. After the control experiments were completed, but on a separate day, an osmotic pump designed to deliver a constant infusion of $\mathrm{NE}(0.5 \mu \mathrm{g} / \mathrm{kg} / \mathrm{min})$ or saline was implanted subcutaneously in the neck using lidocaine anesthesia. $10 \mathrm{~d}$ later another osmotic pump with an infusion dose of $30 \%$ of the dose of the first pump, was implanted to reinforce the elevation of plasma catecholamine levels. Experiments with 5-min infusions of NE and ISO were then repeated in the same dogs 3-4 wk after implantation of the osmotic pumps.

Data analysis. Mean values and standard errors were calculated with an IBM PC/AT computer (IBM Instruments, Inc., Dunbury, CT). Significant differences before and after the implantation of pumps were evaluated by Student's $t$ test (28). Significant differences among groups were evaluated by one-way analysis of variance (29) and Duncan's test.

\section{Results}

Catecholamine levels. In the intact group, there was a 20 -fold increase in plasma levels of $\mathrm{NE}$ after the implantation of $\mathrm{NE}$ pumps $(220 \pm 52$ vs. $4,700 \pm 1,295 \mathrm{pg} / \mathrm{ml})$. In the cardiac denervated group, NE pumps increased plasma levels of NE to the same levels as those in intact, NE pump group. In the intact saline pump group, plasma NE levels were similar before and after the saline pump implantation $(265 \pm 38$ vs. $255 \pm 33$ $\mathrm{pg} / \mathrm{ml}$ ).

Pathology. The LV to body weight ratios were significantly greater $(P<0.05)$, both in the cardiac denervated group with NE pumps $(6.4 \pm 0.6 \mathrm{~g} / \mathrm{kg})$ and in the arterial baroreceptor denervated group with NE pumps $(6.3 \pm 0.9 \mathrm{~g} / \mathrm{kg})$, than those in the intact group with saline pumps $(5.0 \pm 0.2 \mathrm{~g} / \mathrm{kg}$ ) (Table I). However, in intact dogs with NE pumps, LV to body weight ratios were not elevated.

Effects of pumps on baseline hemodynamics (Table II). There were no significant effects of saline pumps on baseline hemodynamics. However, at 3-4 wk after implantation of NE pumps, arterial pressure was not changed significantly, but LV $\mathrm{dP} / \mathrm{dt}$ was elevated slightly, but significantly, in all groups.

\section{Table I. Pathology}

\begin{tabular}{lccc}
\hline \multicolumn{1}{c}{ Pump group } & $\begin{array}{c}\text { Body } \\
\text { weight }\end{array}$ & LV weight & $\begin{array}{c}\text { LV weight/ } \\
\text { body weight } \\
\text { ratio }\end{array}$ \\
\hline & $k g$ & $g$ & $\mathrm{~g} / \mathrm{kg}$ \\
Intact saline $(n=9)$ & $22.8 \pm 1.4$ & $114 \pm 7.5$ & $5.0 \pm 0.2$ \\
Intact NE $(n=11)$ & $21.2 \pm 1.4$ & $108 \pm 5.6$ & $5.2 \pm 0.2$ \\
Cardiac denervated saline $(n=8)$ & $19.5 \pm 0.7$ & $114 \pm 6.8$ & $5.8 \pm 0.2$ \\
Cardiac denervated NE $(n=7)$ & $19.2 \pm 0.6$ & $122 \pm 8.4$ & $6.4 \pm 0.6^{*}$ \\
$\begin{array}{l}\text { Arterial baroreceptor denervated } \\
\quad \text { NE }(n=5)\end{array}$ & $19.1 \pm 0.8$ & $122 \pm 22$ & $6.3 \pm 0.9^{*}$ \\
& & & \\
& & &
\end{tabular}

* Different from intact saline pump group, $P<0.05$. 
Table II. Baseline Hemodynamics Before and After Pumps

\begin{tabular}{lcc}
\hline & $\begin{array}{c}\text { Before } \\
\text { pumps }\end{array}$ & After pumps \\
\hline & & \\
\hline Left ventricular pressure (mmHg) & & \\
Intact dogs with saline pumps & $123 \pm 2$ & $125 \pm 4$ \\
Intact dogs with saline pumps (GB)* & $107 \pm 5$ & $119 \pm 6$ \\
Intact dogs with NE pumps & $122 \pm 3$ & $129 \pm 2$ \\
Intact dogs with NE pumps (GB) & $115 \pm 4$ & $121 \pm 6$ \\
CD dogs with NE pumps & $117 \pm 2$ & $120 \pm 7$ \\
ABD dogs with NE pumps & $117 \pm 4$ & $129 \pm 6$ \\
Left ventricular dP/dt (mmHg/s) & & \\
Intact dogs with saline pumps & $3,053 \pm 118$ & $3,274 \pm 138$ \\
Intact dogs with saline pumps (GB) & $2,231 \pm 136$ & $2,372 \pm 125$ \\
Intact dogs with NE pumps & $2,928 \pm 180$ & $3,606 \pm 199^{\ddagger}$ \\
Intact dogs with NE pumps (GB) & $2,357 \pm 174$ & $3,106 \pm 196^{\ddagger}$ \\
CD dogs with NE pumps & $2,384 \pm 226$ & $3,214 \pm 288^{\ddagger}$ \\
ABD dogs with NE pumps & $2,883 \pm 215$ & $3,604 \pm 379^{\ddagger}$ \\
Mean arterial pressure (mmHg) & & \\
Intact dogs with saline pumps & $97 \pm 3$ & $97 \pm 4$ \\
Intact dogs with saline pumps (GB) & $89 \pm 3$ & $94 \pm 3$ \\
Intact dogs with NE pumps & $96 \pm 3$ & $96 \pm 3$ \\
Intact dogs with NE pumps (GB) & $97 \pm 4$ & $96 \pm 5$ \\
CD dogs with NE pumps & $92 \pm 2$ & $93 \pm 3$ \\
ABD dogs with NE pumps & $90 \pm 3$ & $89 \pm 6$ \\
Heart rate (beats/min) & & \\
Intact dogs with saline pumps & $94 \pm 4$ & $93 \pm 4$ \\
Intact dogs with saline pumps (GB) & $124 \pm 3$ & $122 \pm 6$ \\
Intact dogs with NE pumps & $90 \pm 4$ & $85 \pm 4$ \\
Intact dogs with NE pumps (GB) & $123 \pm 2$ & $142 \pm 9^{\ddagger}$ \\
CD dogs with NE pumps & $107 \pm 3$ & $142 \pm 12^{\ddagger}$ \\
ABD dogs with NE pumps & $103 \pm 4$ & $92 \pm 6$ \\
\hline & & \\
\hline & & \\
& & \\
& & \\
& & \\
& & \\
\hline
\end{tabular}

* GB, Ganglionic blockade; ABD, arterial baroreceptor denervated; $\mathrm{CD}$, cardiac denervated.

${ }^{\ddagger} P<0.05$.
Effects of NE and ISO before and after saline pumps in intact conscious dogs $(n=9)$. There were no significant differences in response to the acute challenges to NE or ISO before and after implantation of saline pumps (Table III). In the presence of ganglionic blockade responses to NE and ISO were also similar before and after the implantation of saline pumps (Table IV).

Effects of NE and ISO before and after NE pumps in intact conscious $\operatorname{dogs}(n=11)$. The changes from baseline for NE and ISO are shown in the absence of ganglionic blockade in Table III and in the presence of ganglionic blockade in Table IV. Dose responses to NE are shown in the dogs with NE pumps in the absence (Fig. 1, left) and presence (Fig. 1, right) of ganglionic blockade. Dose responses to ISO are shown in the dogs with NE pumps in the absence (Fig. 2, left) and presence (Fig. 2 , right) of ganglionic blockade. Only those dogs with arterial pressure controlled during ISO infusion are included in Tables III and IV. In dogs with NE pumps, responses of $\mathrm{LV} \mathrm{dP/dt} \mathrm{to}$ acute challenges to NE in the absence of ganglionic blockade were not different before and after implantation of NE pumps (Table III, Fig. 1). However, in the presence of ganglionic and $\alpha_{1}$-adrenergic blockade, acute challenges to NE increased LV $\mathrm{dP} / \mathrm{dt}$ less $(P<0.01)$ after the implantation of NE pumps than before the pumps (Table IV, Fig. 1). In those dogs studied with ganglionic, but not $\alpha_{1}$-adrenergic receptor blockade, significant decreases in responsiveness of $\mathrm{LV} \mathrm{dP} / \mathrm{dt}$ to acute $\mathrm{NE}$ challenges were also observed. In contrast to $\mathrm{NE}$, acute challenges to ISO increased LV dP/dt less $(P<0.01)$ after the implantation of NE pumps than before, even in the absence of ganglionic blockade (Table III, Fig. 2), as well as in the presence of ganglionic blockade (Table IV, Fig. 2). Heart rate responses to NE were not different in response to acute NE challenge before or after NE pumps in the absence of ganglionic blockade. In the presence of ganglionic blockade the positive chronotropic responses to NE tended to be less $(P=0.10)$. However, positive chronotropic responses to ISO were reduced $(P<0.05)$ after implantation of NE pumps even in the absence

Table III. Effects of NE $(0.4 \mu \mathrm{g} / \mathrm{kg} / \mathrm{min})$ and ISO $(0.4 \mu \mathrm{g} / \mathrm{kg} / \mathrm{min})$ on Intact Dogs with Either Saline or NE Pumps (No Blockade)

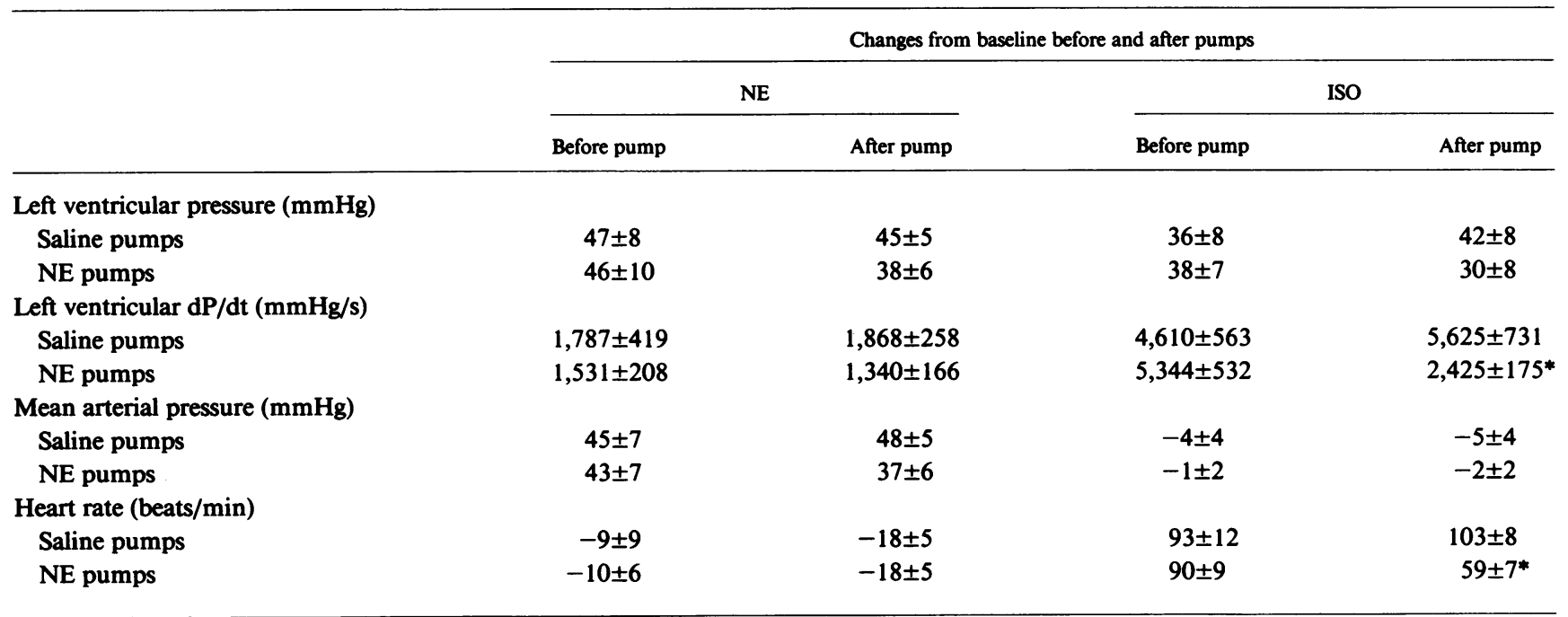

* Different from the values before pumps: ${ }^{*} P<0.05$. 


\begin{tabular}{|c|c|c|c|c|}
\hline & \multicolumn{4}{|c|}{ Change from baseline before and after pumps } \\
\hline & Before pump & After pump & Before pump & After pump \\
\hline \multicolumn{5}{|c|}{ Left ventricular pressure $(\mathbf{m m H g})$} \\
\hline Saline pumps & $54 \pm 12$ & $70 \pm 15$ & $48 \pm 10$ & $71 \pm 19$ \\
\hline Saline pumps & $4,300 \pm 978$ & $3,974 \pm 411$ & $7,746 \pm 1096$ & $6,719 \pm 596$ \\
\hline NE pumps & $3,656 \pm 468$ & $1,459 \pm 200^{*}$ & $7,631 \pm 749$ & $4,293 \pm 662^{*}$ \\
\hline \multicolumn{5}{|c|}{ Mean arterial pressure (mmHg) } \\
\hline Saline pumps & $32 \pm 10$ & $24 \pm 7$ & $1 \pm 1$ & $0 \pm 1$ \\
\hline NE pumps & $25 \pm 5$ & $10 \pm 5^{*}$ & $1 \pm 1$ & $-1 \pm 0$ \\
\hline
\end{tabular}

*, Different from the values before pumps: ${ }^{*} P<0.01,{ }^{\ddagger} P<0.05$.

of ganglionic blockade and were still reduced $(P<0.05)$ in response to ISO in the presence of ganglionic blockade.

In three dogs with NE pumps, the effects of NE were examined with heart rate held constant and in the presence and absence of atropine. With heart rate constant, NE $(0.4 \mu \mathrm{g} / \mathrm{kg} /$ min) increased $\mathrm{LV} \mathrm{dP} / \mathrm{dt}$ by $1,637 \pm 239 \mathrm{mmHg} / \mathrm{s}$ before $\mathrm{NE}$ pumps and by a similar amount $(1,603 \pm 136 \mathrm{mmHg} / \mathrm{s})$ after NE pumps. However, in the presence of atropine but in the
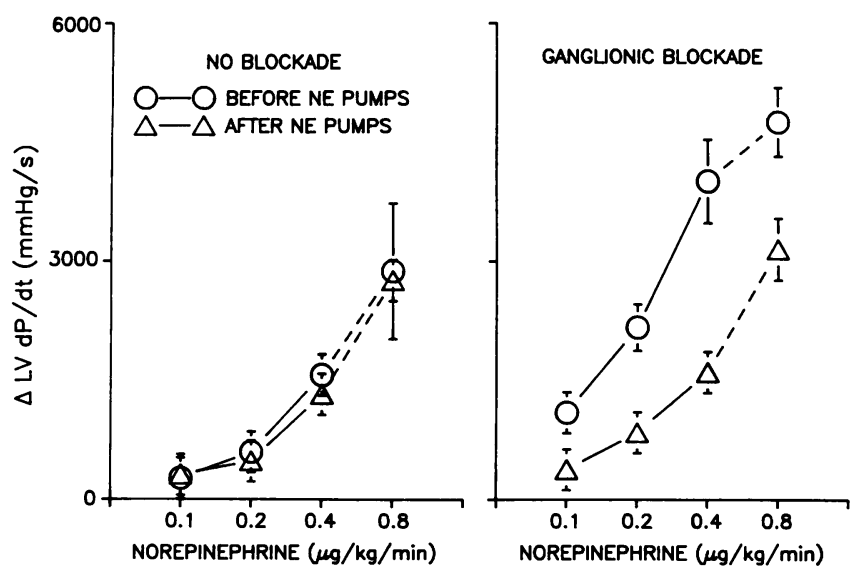

Figure 1. The effects of acute challenges to NE $(0.1,0.2,0.4,0.8$ $\mu \mathrm{g} / \mathrm{kg} / \mathrm{min}$ ) in the absence (left) and in the presence (right) of ganglionic blockade on the measurement of LV dP/dt, are shown before (open circles) and after (open triangles) chronic elevation of plasma $\mathrm{NE}$ levels in conscious dogs with intact cardiac nerves. No functional desensitization to NE challenges was observed without blockade; functional desensitization to NE, i.e., depressed responses of $L V$ $\mathrm{dP} / \mathrm{dt}$, was observed in the presence of ganglionic blockade. Using regression analysis there were no differences between responses before and after NE pumps in the absence of ganglionic blockade, but there was a significant difference $(P<0.01)$ between response to NE in the dogs before and after NE pumps with the presence of ganglionic blockade. Only three dogs in this group were examined at the dose of $0.8 \mu \mathrm{g} / \mathrm{kg} / \mathrm{min}$ (dotted line). absence of ganglionic blockade, NE $(0.4 \mu \mathrm{g} / \mathrm{kg} / \mathrm{min})$ increased LV dP/dt by a lesser amount $(P<0.05,2,218 \pm 498 \mathrm{mmHg} / \mathrm{s})$ after NE pumps as compared with the responses before NE pumps $(4,360 \pm 771 \mathrm{mmHg} / \mathrm{s})$. Thus, desensitization to $\mathrm{NE}$ was not observed while simply holding heart rate constant, but was demonstrated clearly in the presence of muscarinic blockade with atropine. In these dogs similar amounts of desensitization to NE were observed in the presence of ganglionic blockade with atropine, either in the presence or absence of ventricular pacing. In these same three dogs, the effects of ISO challenges were also examined. With heart rate constant, ISO $(0.4 \mu \mathrm{g} / \mathrm{kg} /$ min) increased LV dP/dt by a lesser amount $(P<0.05)$ after
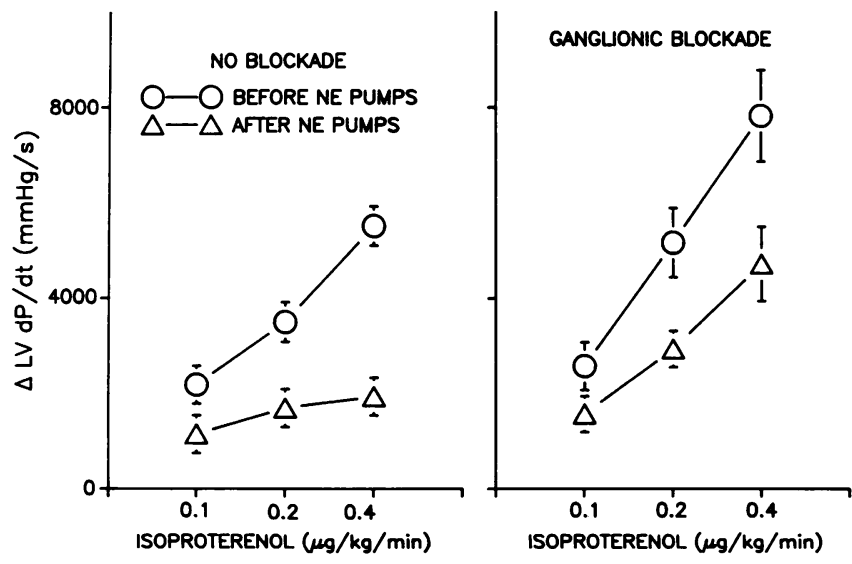

Figure 2. The effects of acute challenges to ISO $(0.1,0.2,0.4 \mu \mathrm{g} / \mathrm{kg} /$ $\mathrm{min}$ ) on the measurement of $\mathrm{LV} \mathrm{dP/dt}$, without blockade are shown in the absence (left) and presence (right) of ganglionic blockade before (open circles) and after (open triangles) the chronic elevation of plasma NE levels in conscious dogs with intact cardiac nerves. Functional desensitization to ISO, i.e., depressed responses of $\mathrm{LV} \mathrm{dP/dt}$, was observed both in the absence and presence of ganglionic blockade. Using regression analysis, there was a significant difference $(P$ $<0.01$ ) between responses before and after pumps both in the absence and presence of ganglionic blockade. 
Table $V$. Effects of NE $(0.4 \mu \mathrm{g} / \mathrm{kg} / \mathrm{min})$ on Cardiac Denervated Dogs with Either Saline or NE Pumps (No Blockade)

\begin{tabular}{lcc}
\hline & \multicolumn{2}{c}{$\begin{array}{c}\text { Change from baseline before } \\
\text { and after pumps }\end{array}$} \\
\cline { 2 - 3 } & Before pump & After pump \\
\hline $\begin{array}{l}\text { Left ventricular pressure (mmHg) } \\
\text { Saline pumps }\end{array}$ & $101 \pm 7$ & $101 \pm 6$ \\
NE pumps & $133 \pm 12$ & $67 \pm 6^{*}$ \\
Left ventricular dP/dt (mmHg/s) & & \\
$\quad$ Saline pumps & $8,605 \pm 1,089$ & $7,989 \pm 1,361$ \\
NE pumps & $9,901 \pm 1,404$ & $2,690 \pm 306^{*}$ \\
Mean arterial pressure (mmHg) & & \\
$\quad$ Saline pumps & $75 \pm 8$ & $77 \pm 5$ \\
NE pumps & $84 \pm 10$ & $75 \pm 7$ \\
Heart rate (beats/min) & & \\
Saline pumps & $69 \pm 16$ & $71 \pm 13$ \\
NE pumps & $116 \pm 16$ & $36 \pm 2^{*}$ \\
\hline
\end{tabular}

* Different from the value before pumps, $P<0.01$.

NE pumps $(2,036 \pm 397 \mathrm{mmHg} / \mathrm{s})$ as compared with increases before $\mathrm{NE}$ pumps $(5,361 \pm 1,080 \mathrm{mmHg} / \mathrm{s})$. In the presence of atropine, but in the absence of ganglionic blockade, ISO $(0.4$ $\mu \mathrm{g} / \mathrm{kg} / \mathrm{min})$ increased LV dP/dt by a lesser amount $(P<0.05)$ after NE pumps $(3,283 \pm 385 \mathrm{mmHg} / \mathrm{s})$ as compared with increases before NE pumps $(6,186 \pm 665 \mathrm{mmHg} / \mathrm{s})$. Similar results were observed in the animals with heart rate held constant. Thus, similar amounts of desensitization were observed whether or not heart rate was held constant and both in the presence and absence of atropine.

Effects of $N E$, before and after saline pumps in cardiac denervated conscious dogs without ganglionic blockade $(n=9)$. There were no significant differences either in baseline values

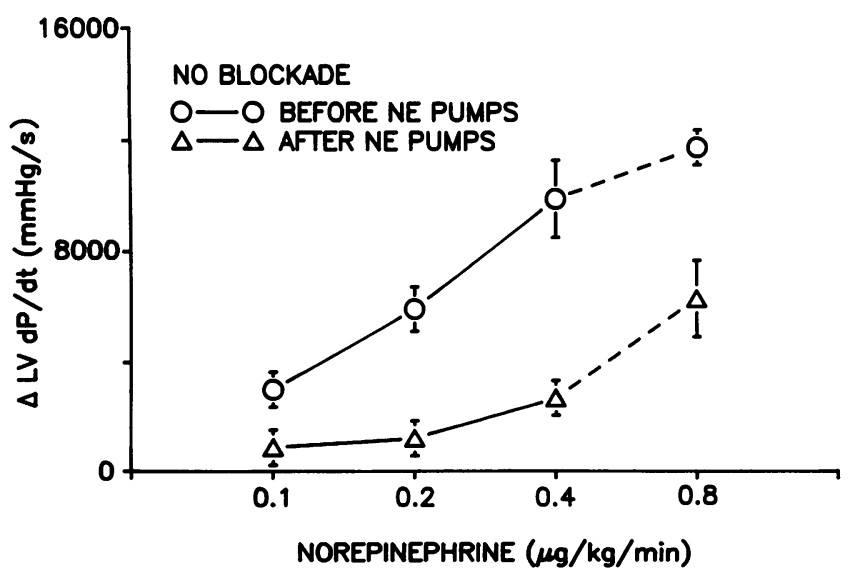

Figure 3. The effects of acute challenges to NE $(0.1,0.2,0.4,0.8$ $\mu \mathrm{g} / \mathrm{kg} / \mathrm{min}$ ) on the measurement of $\mathrm{LV} \mathrm{dP} / \mathrm{dt}$, in the absence of ganglionic blockade, are shown before (open circles) and after (open triangles) chronic elevation of plasma NE levels in conscious dogs with cardiac denervation. Functional desensitization to NE, i.e., depressed response of $\mathrm{LV} \mathrm{dP/dt}$, was observed in the absence of ganglionic blockade. Only four dogs in this group were examined at the dose of $0.8 \mu \mathrm{g} / \mathrm{kg} / \mathrm{min}$ (dotted lines). Using regression analysis, there was a significant difference $(P<0.01)$ between responses before and after pumps.

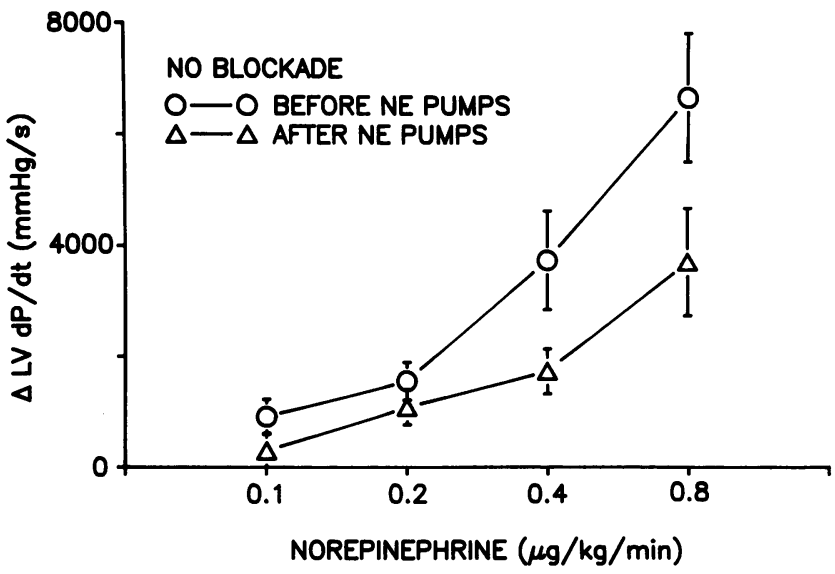

Figure 4. The effect of acute challenges to NE $(0.1,0.2,0.4,0.8$ $\mu \mathrm{g} / \mathrm{kg} / \mathrm{min}$ ) on the measurement of $\mathrm{LV} \mathrm{dP} / \mathrm{dt}$, in the absence of ganglionic blockade are shown before (open circles) and after (open triangles) chronic elevation of plasma NE levels in conscious dogs with arterial baroreceptor denervation. Functional desensitization to NE, i.e., depressed responses of $\mathrm{LV} \mathrm{dP/dt}$, was observed in the absence of ganglionic blockade. Using regression analysis, there was a significant difference $(P<0.02)$ between responses before and after pumps.

or in responses to the acute challenges to NE, before and after implantation of saline pumps (Table V). However, responses of $\mathrm{LV} \mathrm{dP/dt}$ to NE were greater than observed in intact dogs, reflecting denervation supersensitivity (25).

Effects of NE before and after NE pumps in cardiac denervated conscious dogs without ganglionic blockade $(n=7)$. Dose responses to NE are shown in the dogs with NE pumps in Fig. 3. The changes from baseline for one dose of NE, before and after implantation of NE pumps are shown in Table V. In dogs with NE pumps, responses of $\mathrm{LV} \mathrm{dP/dt} \mathrm{to} \mathrm{acute} \mathrm{challenges} \mathrm{to}$ NE were significantly depressed $(P<0.01)$ after the chronic infusion of NE (Table V, Fig. 3). Heart rate responses to NE were also significantly reduced in these dogs.

Effects of NE before and after NE pumps in baroreceptor denervated conscious dogs without ganglionic blockade $(n=5)$. Dose responses to NE are shown in the dogs with NE pumps in Fig. 4. The changes from baseline for one dose of NE before and after implantation of NE pumps are shown in Table VI. In dogs with NE pumps, responses of $\mathrm{LV} \mathrm{dP/dt}$ to acute challenges to NE were depressed after the chronic infusion of NE $(P<0.05$; Table VI, Fig. 4). Responses of heart rate to NE also tended to be reduced in these dogs after chronic infusion of NE.

Table VI. Effects of NE $(0.4 \mu \mathrm{g} / \mathrm{kg} / \mathrm{min})$ on Arterial Baroreceptor Denervated Dogs with Norepinephrine Pumps

\begin{tabular}{lcc}
\hline & \multicolumn{2}{c}{$\begin{array}{c}\text { Change from baseline before } \\
\text { and after pumps }\end{array}$} \\
\cline { 2 - 3 } & Before pump & After pump \\
\hline Left ventricular pressure (mmHg) & $99 \pm 13$ & $81 \pm 13$ \\
Left ventricular dP/dt (mmHg/s) & $3,732 \pm 896$ & $1,725 \pm 408^{*}$ \\
Mean arterial pressure (mmHg) & $89 \pm 3$ & $70 \pm 12$ \\
Heart rate (beats/min) & $25 \pm 14$ & $1 \pm 7$
\end{tabular}

* Different from the value before pumps, $P<0.05$. 


\section{Discussion}

It is generally accepted that chronic catecholamine administration results in catecholamine desensitization (30). Broad support for this concept can be found in the baseline hemodynamic data from all groups of animals studied, regardless of whether experiments were conducted in intact dogs or dogs with arterial baroreceptor denervation or cardiac denervation. While baseline values of $\mathrm{LV} \mathrm{dP/dt}$ were generally modestly increased, mean arterial pressure was not different from baseline, even in the animals with chronic arterial baroreceptor denervation. Thus, prolonged exposure to 20-fold elevations in plasma levels of $\mathrm{NE}$, which would acutely increase $\mathrm{LV} \mathrm{dP/dt}$ and arterial pressure markedly, do not result in persistent hypertension and only elicit modest elevation in LV dP/dt.

One might predict that normalization of arterial pressure in the presence of chronically elevated NE levels might be mediated by arterial baroreceptor or cardiac reflexes. Surprisingly, the results of the present investigation do not support this hypothesis, since arterial pressure was normalized equally well in animals with chronic arterial baroreceptor denervation or chronic cardiac denervation. Thus reflexes are not primarily responsible for normalization of arterial pressure with chronic NE exposure. Rather, other mechanisms, e.g., desensitization, must be involved.

The major goal of the current investigation was to determine if acute challenges of sympathomimetic amines in the presence of chronically elevated levels of NE resulted in reduced inotropic and chronotropic responsiveness, i.e., functional desensitization. Prior studies examining the effects of desensitization to catecholamines have been conducted, primarily in vitro $(14,18,19,23)$ or in acutely prepared anesthetized preparations $(15-17,20,21)$ where neural control mechanisms are blunted, if not absent. The underlying hypothesis of the present investigation was that neural mechanisms modify importantly the manner in which catecholamine desensitization is expressed primarily to the neurotransmitter NE. In the current experiments in which chronically elevated levels of $\mathrm{NE}$ were examined for $1 \mathrm{mo}$ in conscious animals, desensitization of inotropic and chronotropic responses to the specific $\beta$ adrenergic agonist ISO was observed. However, surprisingly, there was no desensitization of either inotropy or chronotropy to the neurotransmitter NE in conscious animals with all reflexes intact. There are several important differences that have to be kept in mind between NE on the one hand, and ISO, a synthetic sympathomimetic amine, on the other. ISO is not taken up by cardiac nerves and also stimulates only $\beta$-adrenergic receptors, whereas NE, the sympathetic neurotransmitter, is taken up by the cardiac nerves and stimulates both $\alpha$ - and $\beta$-adrenergic receptors. Furthermore, because of peripheral $\alpha$-adrenergic receptor stimulation associated with NE, arterial pressure rises and elicits arterial baroreceptor reflex buffering, thereby attenuating direct effects of NE on the heart (26). Conversely, ISO unloads arterial baroreflexes, which results in amplification of the inotropic and chronotropic responses.

One of the major hypotheses of the current investigation was that reflex mechanisms prevent the expression of functional desensitization to NE in these chronic animals. To test that hypothesis, we examined the effects of chronically elevated $\mathrm{NE}$ in animals in the presence and absence of ganglionic blockade. After ganglionic blockade, clearcut desensitization to NE was demonstrated. We induced two other maneuvers to eliminate the neuronal and reflex effects on the heart; one involved chronic cardiac denervation and the other involved arterial baroreceptor denervation, leaving the cardiac nerves intact. By either mechanism, the former where supersensitivity occurs, and the latter where supersensitivity is not present, clearcut desensitization to NE was observed even in the absence of autonomic blockade. These experiments all suggest that under conditions of chronic NE exposure that reflex mechanisms and cardiac nerves, utilizing reuptake mechanisms, mask the expression of desensitization to an acute NE challenge. While a prior study noted weak or absent desensitization to NE in the presence of chronic $\mathrm{NE}$ exposure, the mechanism for this unexpected finding was not examined (21).

In the current experiments it was more difficult to demonstrate desensitization of responses to heart rate than to $\mathrm{LV}$ $\mathrm{dP} / \mathrm{dt}$, i.e., an index of LV inotropy. However, again in intact dogs with NE pumps after ganglionic blockade or in cardiac denervated dogs, or in arterial baroreceptor denervated dogs, desensitization of heart rate responses was also observed. Since major differences in heart rate response were not observed in response to NE challenges before and after chronic NE exposure, it was felt unlikely that changes in heart rate could account for differences in inotropic responses to NE and ISO challenges in the dogs with chronic NE exposure. However, to address this possibility directly, challenges to NE and ISO were examined in three animals with heart rate held constant. The data were similar in these experiments as compared with the remaining experiments where heart rate was allowed to vary. Thus, heart rate, per se, was not responsible for the findings. On the other hand, parasympathetic blockade with atropine induced markedly different effects. Under these conditions expression of desensitization to NE challenges was observed readily, as occurred in the presence of ganglionic blockade and arterial baroreceptor denervation, further pointing out the importance of reflexes in mediating functional expression of desensitization to NE, but not to ISO.

These data taken together raise an intriguing hypothesis, i.e., that chronic NE desensitizes (or resets) the sympathetic component of the arterial baroreceptor reflex as well as postjunctional $\beta$-adrenergic receptor pathways. Thus, the failure to observe desensitization to NE in intact, conscious dogs with chronically elevated NE levels could be explained by alterations in the arterial baroreflex. The initial inotropic response to an acute NE challenge is the result of the direct positive inotropic effects minus the reflex negative inotropic and chronotropic effects. Conceivably, after chronic exposure to $\mathrm{NE}$ the baroreflex-mediated negative inotropic effects mediated through the sympathetic nervous system were less potent, thereby leaving the direct positive inotropic effects of $\mathrm{NE}$ unopposed. The mechanism for this might involve resetting at the receptor in the central nervous system or peripherally. In support of this concept, note that the absolute increases in LV $\mathrm{dP} / \mathrm{dt}$ induced by acute NE challenges were similar after NE pumps in intact dogs with or without ganglionic blockade and also in the group of dogs with arterial baroreceptor denervation. Only the increases in $\mathrm{LV} \mathrm{dP/dt}$ induced by acute NE challenges were greater before NE pumps in intact dogs with ganglionic blockade and arterial baroreceptor denervation. Thus, it was a reduction in response from a higher level before 
NE pumps to the same level observed in intact dogs without blockade that allowed for expression of desensitization to acute NE challenge in the dogs with reflexes blocked. The experiments with acute ISO challenge further support this concept. With ISO the converse situation appears, i.e., the inotropic response is the sum of the direct $\beta$-adrenergic effects and the reflex inotropic responses. After chronic NE pumps the desensitization to an acute ISO challenge was actually more apparent in the absence of ganglionic blockade as compared with results in the presence of ganglionic blockade, just the converse of what was observed with acute NE challenges.

Another important difference between NE and ISO is that $\mathrm{NE}$ is an $\alpha$ - as well as $\beta$-adrenergic receptor agonist. The current study was not designed to assess peripheral vascular $\alpha$ adrenergic receptor desensitization. However, in so far as the rise in mean arterial pressure reflects in a rough manner peripheral vasoconstrictor activity of $\mathrm{NE}$, it is interesting to note that the pressor response to NE was only significantly desensitized after reflex effects were eliminated in the presence of ganglionic blockade.

Because of the chronic nature of the experiments, inactive metabolites of NE could have been produced in the implanted pumps, which might affect the measurement of plasma levels of NE. However, an excellent agreement has been reported between the radioenzymatic method and high-performance liquid chromatography, which measures NE specifically (31). In a previous, similar study (32) plasma levels of catecholamine were measured with high performance liquid chromatography as well as by the radioenzymatic method, and the plasma levels of NE were demonstrated to be similar to ours.

In addition to desensitization, chronic exposure to NE (33) has been shown to induce cardiac hypertrophy, and at very large doses to induce myocardial necrosis and reparative fibrosis $(17,34)$. While we observed increases in $\mathrm{LV} /$ body weight ratios in dogs with NE pumps, the increases were not significant. However, the dogs with cardiac denervation and the dogs with arterial baroreceptor denervation and NE pumps exhibited mild cardiac hypertrophy. In this connection, a recent study by Brush et al. (35) postulated that altered reuptake of NE, a phenomenon intrinsic to the cardiac denervation model, may be the cause of hypertrophy in patients with hypertrophic cardiomyopathy. Gross examination of the hearts in the present study failed to reveal necrosis or fibrosis. In other studies using similar models, histologic examination also failed to reveal significant fibrosis (36).

A recent study from this laboratory demonstrated that the biochemical mechanisms involved in desensitization were complex. They did not simply involve downregulation of $\beta$ adrenergic receptor density but rather involved uncoupling of the $\beta$-adrenergic receptor and decreased activity of the stimulatory guanine nucleotide regulatory protein, $G_{s}(37)$. The present investigation suggests that the mechanisms are even more complicated than previously thought in that the presence or absence of cardiac and/or arterial baroreceptor nerves plays a major role in allowing the expression of functional desensitization to NE, but not to ISO. It is interesting to speculate that these data may be extrapolated to the state of chronic heart failure, which is often characterized by desensitization to catecholamines $(1,5,6,9)$. While one difference between some clinical states of heart failure and the current experiments is the concomitant increase in circulating levels of epinephrine, as well as norepinephrine, it is also important to note that heart failure is marked by elements of cardiac denervation, at least in terms of catecholamine depletion $(2,38)$, and also by impaired arterial baroreflex control $(39,40)$. Thus, impaired neural control of the heart by cardiac nerves and arterial baroreflexes may be critical in the functional expression of catecholamine desensitization in heart failure.

\section{Acknowledgments}

This work was supported in part by United States Public Health Service grants HL-38070, HL-33107, HL-37404, and RR-00168. J. Nejima and N. Uemura were the recipients of Fellowship grants MHA 13-437-867 and MHA 13-434-878 from The American Heart Association, Massachusetts Affiliate. Dr. Dorothy Vatner is supported by Research Career Development Award K04 HL-01909.

\section{References}

1. Bristow, M. R., R. Ginsburg, W. Minobe, R. S. Cubicciotti, W. S. Sageman, K. Lurie, M. E. Billingham, D. C. Harrison, and E. B. Stinson. 1982. Decreased catecholamine sensitivity and $\beta$-adrenergicreceptor density in failing human hearts. N. Engl. J. Med. 307:205211.

2. Chidsey, C. A., E. Braunwald, and A. G. Morrow. 1965. Catecholamine excretion and cardiac stores of norepinephrine in congestive heart failure. Am. J. Med. 39:442-451.

3. Colucci, W. S., R. W. Alexander, G. H. Williams, R. E. Rude, B. L. Holman, M. A. Konstam, J. Wynne, G. H. Mudge, Jr., and E. Braunwald. 1981. Decreased lymphocyte beta-adrenergic receptor density in patients with heart failure and tolerance to the beta-adrenergic agonist pirbuterol. N. Engl. J. Med. 305:185-190.

4. Cryer, P. E. 1980. Physiology and pathophysiology of the human sympathoadrenal neuroendocrine system. $N$. Engl. J. Med. 303:436444.

5. Fowler, M. B., J. A. Laser, G. L. Hopkins, W. Minobe, and M. R. Bristow. 1986. Assessment of the $\beta$-adrenergic receptor pathway in the intact failing human heart: progressive receptor down-regulation and subsensitivity to agonist response. Circulation. 74:1290-1302.

6. Ginsburg, R., M. R. Bristow, M. E. Billingham, E. B. Stinson, J. S. Schroeder, and D. C. Harrison. 1983. Study of the normal and failing isolated human heart: decreased response of failing heart to isoproterenol. Am. Heart J. 106:535-540.

7. Levine, T. B., G. S. Francis, S. R. Goldsmith, A. B. Simon, and J. N. Cohn. 1982. Activity of the sympathetic nervous system and renin-angiotensin system assessed by plasma hormone levels and their relation to hemodynamic abnormalities in congestive heart failure. Am. J. Cardiol. 49:1659-1666.

8. Pasternac, A., J. F. Tubau, P. E. Puddu, R. B. Krol, and J. de Champlain. 1982. Increased plasma catecholamine levels in patients with symptomatic mitral valve prolapse. Am. J. Med. 73:783-790.

9. Pouleur, H., M. F. Rousseau, C. Hanet, H. F. Marlow, and A. A. Charlier. 1987. Left ventricular sensitivity to $\beta$-adrenoreceptor-stimulating drugs in patients with ischemic heart disease and varying degrees of ventricular dysfunction. Circ. Res. 61(Suppl. I):191-195.

10. Thomas, J. A., and B. H. Marks. 1978. Plasma norepinephrine in congestive heart failure. Am. J. Cardiol. 41:233-243.

11. Blacket, R. B., G. W. Pickering, and G. M. Wilson. 1950. The effects of prolonged infusions of noradrenaline and adrenaline on the arterial pressure of the rabbit. Clin. Sci. 9:247-257.

12. Essex, H. E. 1952. Further observations of certain responses of tolerant and control animals to massive doses of epinephrine. Am. J. Physiol. 171:78-86.

13. Vigran, I. M., and H. E. Essex. 1950. Studies on physiologic effects of large doses of epinephrine. Am. J. Physiol. 162:230-242.

14. Chang, H. Y., R. M. Klein, and G. Kunos. 1982. Selective 
desensitization of cardiac beta adrenoceptors by prolonged in vivo infusion of catecholamines in rats. J. Pharmacol. Exp. Ther. 221:784789.

15. Hayes, J. S., G. D. Pollock, and R. W. Fuller. 1984. In vivo cardiovascular responses to isoproterenol, dopamine and tyramine after prolonged infusion of isoproterenol. J. Pharmacol. Exp. Ther. 231:633-639.

16. Hayes, J. S., N. Bowling, and G. D. Pollock. 1985. Effects of beta adrenoceptor down-regulation on the cardiovascular responses to the stereoisomers of dobutamine. J. Pharmacol. Exp. Ther. 235:58-65.

17. Lee, J. C., and S. E. Downing. 1982. Ventricular function in norepinephrine-induced cardiomyopathic rabbits. Am. J. Physiol. 242:(Heart Circ. Physiol. 11):H191-H196.

18. Marsh, J. D., W. H. Barry, E. J. Neer, R. W. Alexander, and T. W. Smith. 1980. Desensitization of chick embryo ventricle to the physiological and biochemical effects of isoproterenol (evidence for uncoupling of the $\beta$ receptor-adenylate cyclase complex). Circ. Res. 47:493-501.

19. Nanoff, C., M. Freissmuth, E. Tuisl, and W. Schutz. 1989. A different desensitization pattern of cardiac $\beta$-adrenoceptor subtypes by prolonged in vivo infusion of isoprenaline. J. Cardiovasc. Pharmacol. 13:198-203.

20. Newman, W. H. 1977. A depressed response of left ventricular contractile force to isoproterenol and norepinephrine in dogs with congestive heart failure. Am. Heart J. 93:216-221.

21. Siri, F. M. 1985. Chronic norepinephrine infusion and adrenergic function of hypertrophied hearts. Am. J. Physiol. 248(Heart Circ. Physiol. 17):H485-H492.

22. Toews, M. L. 1987. Comparison of agonist-induced changes in $\beta$ : and $\alpha_{1}$-adrenergic receptors of DDT DF- $_{1}$ cells. Mol. Pharmacol. 31:58-68.

23. Tse, J., J. R. Powell, C. A. Baste, R. E. Priest, and J. F. Kuo. 1979. Isoproterenol-induced cardiac hypertrophy: modifications in characteristics of $\beta$-adrenergic receptor, adenylate cyclase, and ventricular contraction. Endocrinology. 105:246-255.

24. Randall, W. C., M. P. Kaye, J. X. Thomas, and M. J. Barber. 1980. Intrapericardial denervation of the heart. J. Surg. Res. 29:101109.

25. Vatner, D. E., M. Lavallee, J. Amano, A. Finizola, C. J. Homcy, and S. F. Vatner. 1985. Mechanisms of supersensitivity to sympathomimetic amines in the chronically denervated heart of the conscious dog. Circ. Res. 57:55-64.

26. Vatner, S. F., J. D. Rutherford, and H. R. Ochs. 1979. Baroreflex and vagal mechanisms modulating left ventricular contractile responses to sympathomimetic amines in conscious dogs. Circ. Res. 44:195-207.
27. DaPrada, M., and G. Zurcher. 1976. Simultaneous radioenzymatic determination of plasma and tissue adrenaline, noradrenaline and dopamine within the femtomole range. Life Sci. 19:1161-1174.

28. Armitage, P. 1971. Statistical Methods in Medical Research. Blackwell Scientific Publications, Oxford. 116-118.

29. Winer, B. J. 1971. Statistical Principles in Experimental Design. 2nd ed. McGraw-Hill Book Co., New York. 149-232.

30. Harden, T. K. 1983. Agonist-induced desensitization of the $\beta$-adrenergic receptor-linked adenylate cyclase. Pharmacol. Rey. 35:5-32.

31. Hjemdahl, P., M. Daleskog, and T. Kahan. 1979. Determination of plasma catecholamines by high performance liquid chromatography with electrochemical detection: comparison with a radioenzymatic method. Life Sci. 25:131-138.

32. King, B. D., D. Sack, M. R. Kichuk, and T. H. Hintze. 1987. Absence of hypertension despite chronic marked elevations in plasma norepinephrine in conscious dogs. Hypertension (Dallas). 9:582-590.

33. Laks, M. M., F. Morady, and H. J. C. Swan. 1973. Myocardial hypertrophy produced by chronic infusion of subhypertensive doses of norepinephrine in the dog. Chest. 64:75-78.

34. Downing, S. E., and J. C. Lee. 1978. Effects of insulin on experimental catecholamine cardiomyopathy. Am. J. Pathol. 93:339352.

35. Brush, J. E. Jr., G. Eisenhofer, M. Garty, R. Stull, B. J. Maron, R. O. Cannon, III, J. A. Panza, S. E. Epstein, and D. S. Goldstein. 1989. Cardiac norepinephrine kinetics in hypertrophic cardiomyopathy. Circulation. 79:836-844.

36. Patel, M. B., A. V. Loud, P. Anversa, and T. H. Hintze. 1989. Morphometric study of left ventricular subendocardial myocytes in dogs with chronically elevated plasma norepinephrine. Circulation. 80(Suppl.II):II-674. (Abstr.).

37. Vatner, D. E., S. F. Vatner, J. Nejima, N. Uemura, E. E. Susanni, T. H. Hintze, and C. J. Homcy. 1989. Chronic norepinephrine elicits desensitization by uncoupling the $\beta$-receptor. J. Clin. Invest. 84:1741-1748.

38. Vatner, D. E., S. F. Vatner, A. M. Fujii, and C. J. Homcy. 1985. Loss of high affinity cardiac beta adrenergic receptors in dogs with heart failure. J. Clin. Invest. 76:2259-2264.

39. Eckberg, D. L., M. Drabinsky, and E. Braunwald. 1971. Defective cardiac parasympathetic control in patients with heart disease. $N$. Engl. J. Med. 285:877-883.

40. Higgins, C. B., S. F. Vatner, D. L. Eckberg, and E. Braunwald. 1972. Alterations in the baroreceptor reflex in conscious dogs with heart failure. J. Clin. Invest. 51:715-724. 